\title{
CFD Simulations of Cross Natural Ventilation through an Apartment with Modified Inflow Boundary Conditions
}

\author{
Sumei Liu ${ }^{1}$, Wuxuan $\operatorname{Pan}^{1}$, Xiaorui Lin $^{2}$, Ke Qing ${ }^{2}$, Weizhen Zhang ${ }^{2}$, Zhengwei Long ${ }^{1}$, Qingyan \\ Chen $^{3, *}$ \\ ${ }^{1}$ School of Environmental Science and Engineering, Tianjin University, Tianjin, 300072, China \\ ${ }^{2}$ Vanke real estate development co. Itd, Changsha Vanke, Hunan Province, 410000, China \\ ${ }^{3}$ School of Mechanical Engineering, Purdue University, West Lafayette, IN 47905, USA
}

\begin{abstract}
Natural ventilation in buildings can improve indoor air quality and thermal comfort in summer and can reduce the use of air-conditioning. Traditionally the inflow boundary conditions for calculating natural ventilation used weather data from a meteorological station that is often in suburb. The hourly wind velocity from the meteorological station may lead to some errors due to discretized data on hourly basis. This investigation proposed a correlation method to modify the hourly wind velocity from the meteorological station into minutely data by using measured data on the rooftop of a building interested. A CFD simulation using unsteady RNG $\mathrm{k}-\varepsilon$ model was performed to calculate simultaneously the outdoor wind velocity and the crossventilation rate through an apartment in the building. The computed results of outdoor wind velocity and indoor ventilation rate were compared with the experimental data. The results showed that the CFD simulations with the unsteady RNG k- $\varepsilon$ model and the modified inflow boundary conditions could accurately calculate the outdoor wind velocity variations and indoor natural ventilation rate.
\end{abstract}

\section{Introduction}

Natural ventilation can improve indoor air quality by 20 $47 \%$ (Almeida et al., 2017), potentially reduce energy consumption by $8-78 \%$ (Tong et al., 2016), and provide a high level of thermal comfort for occupants (de Dear and Brager, 2002). Unfortunately, natural ventilation cannot be used in all climates, since the weather conditions are an important factor (Larsen, 2006). Certainly, places such as Kunming, China, have favourable weather for natural ventilation. Even in these places, however, it is challenging to design natural ventilation because of the effects of opening size and location (Shetabivash, 2015; Aflaki et al., 2015), the transient interaction between the indoor and outdoor environment, unsteady wind conditions (Chen et al., 2017), irregular urban geometry (van Hooff and Blocken, 2010a), variations in outdoor air quality (Tong et al., 2016), and so on.

The driving force for natural ventilation is the pressure differential created by wind and thermal buoyancy. Therefore, in the design of naturally ventilated buildings, the first step is to obtain reliable meteorological wind information, such as wind speed and direction (Chen,
2004). One can then design natural ventilation by various methods, such as the analytical method, (semi)empirical models, the wind tunnel method, and the computational fluid dynamics (CFD) method.

Natural ventilation can be divided into wind-driven cross ventilation and single-sided ventilation. Wind-driven cross ventilation entails a high flow rate through a building and is more desirable. Therefore, this investigation focused on cross ventilation. Many analytical and (semi-)empirical models have been developed to calculate cross ventilation rate, such as the models proposed by Etheridge and Sandberg (1996), Chu and Wang (2010), and Aynsley (1998). Although these models are both useful and easy to use, they introduce large uncertainties because they do not take major influencing factors into account (van Hooff et al., 2017). The wind tunnel method exhibits good control of the inflow boundary conditions (Jiang et al., 2003) but does not vary wind speed and direction over time and is very expensive. Meanwhile, the CFD method can account for major influencing factors. Although CFD is computationally demanding, its accuracy and reliability in determining the ventilation rate make it an ideal tool for cross-ventilation design (Shirzadi et al., 2018; Ramponia and Blocken, 2012; Hu et al., 2005).

Previously published CFD models for cross-ventilation simulation can be classified into three types, the decoupled modeling method (Jiang and Chen, 2002), compact integration modeling method (Zhai et al., 2000), and coupled modeling method (van Hooff and Blocken, 2010b). The decoupled modeling method simulates indoor airflow separately by assigning fixed pressure at windows, where the pressure is determined at the building façade with solid building blocks for outdoor airflow simulation (Liu et al., 2014). When this method is used, the computing time and capacity are minimal. However, this simple method predicts that airflow enters the exterior windows of an apartment perpendicularly, which is unrealistic and inaccurate. The compact integration modeling method first calculates outdoor airflow with solid building blocks. The method then simulates airflow through and around an apartment in a building with the use of flow information extracted at a certain distance from the building in the outdoor airflow simulation (Zhai et al., 2000). However, the specified distance from the building has an impact on the calculated cross-ventilation rate. The coupled modeling method calculates outdoor wind flow and indoor natural 
ventilation simultaneously (Perén et al, 2015). This method can capture the complex interaction between outdoor wind flow and indoor natural ventilation, and thus it is the most accurate. Unfortunately, the coupled modeling method is the most computationally demanding.

Nevertheless, a number of researchers have adopted the coupled modeling method to investigate cross ventilation. Some researchers have focused on an isolated or generic building (Cheng et al., 2018; Wang and Wong, 2008; Wu et al., 2018). To take into account the influence of surrounding buildings on the airflow around the building of interest, other researchers have considered the sheltering effect of neighbouring buildings on the indoor air flow (Martins and da Graça, 2016; Aflaki et al., 2019; Zhang et al., 2018). Several investigations have explored the indoor cross-ventilation rate using actual urban configurations (van Hooff and Blocken, 2010a; van Hooff and Blocken, 2013), but doing so requires detailed information about urban geometry. It should be noted that all these investigations used hourly wind velocity and direction obtained from a meteorological station as inflow boundary conditions. This was because a meteorological station typically provides hourly data. In reality, cross ventilation should be determined minute by minute or even second by second. Our earlier studies (Liu et al., 2017; Liu et al., 2018) found that, although the hourly wind velocity and direction from a meteorological station may have been the same at two different moments in time, the wind speed measured on a building rooftop varied considerably. Should CFD be used to calculate the wind speed on the rooftop, the results would be the same for the two moments. This is because CFD simulation using hourly wind data cannot account for wind extremes and variations that occur within a given hour.

Thus, appropriate wind information within an hour-long period is prerequisite for obtaining rational wind flow fields, and subsequently the cross-ventilation rate, by means of CFD. Although wind may vary significantly within an hour, hourly meteorological data does not contain this information. Previous studies have not correctly considered the transient characteristics of wind. To fill this gap, the present investigation proposed the use of a correlation method to convert hourly wind data from a meteorological station to minute-by-minute or even second-by-second transient data. The method enabled us to take the unsteady character of the inflow boundary into account and thus maintain the accuracy of the simulation results.

\section{Methods}

This section describes a correlation method for converting hour-by-hour meteorological data from a meteorological station into minute-by-minute data. We then discuss the experimental approach for obtaining wind velocity on a building rooftop and the indoor crossventilation rate in order to validate the method. Finally, this section illustrates the numerical procedure for computing the cross-ventilation flow.
Correlation method for obtaining minute-by-minute wind velocity

Traditionally, the inflow boundary conditions for calculating natural ventilation have used hourly weather data from a meteorological station that is often located in a suburb. The large time interval contributes significant error to the calculated rate because the wind can change significantly within an hour. Our previous studies (Liu et al., 2017; Liu et al., 2018) found that, although the hourly wind velocity and wind direction from the meteorological station may have remained the same within a given period, the wind measured on a building rooftop varied considerably. We suspect that the wind extremes and variations during the period could be the cause of the variation.

To verify the above hypothesis, the ideal approach would be to obtain more detailed wind information from a meteorological station. Unfortunately, the finest time interval in the data provided by a station is one hour. However, a study by Robaa (2003) found a very strong correlation between wind information from a meteorological station and that from a local weather station within the city, as shown in Figure 1.

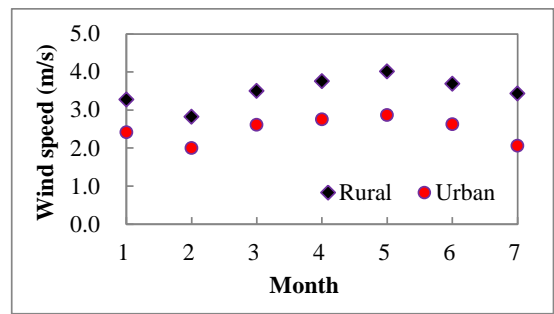

Figure 1: Comparison of mean wind speed in rural and urban areas (Robaa, 2003).

In addition, the ASHRAE Handbook of Fundamentals (2009) provides a correlation equation linking local wind speed on a building rooftop, terrain type, building height, and wind speed from a meteorological station as follows:

$$
U_{H}=U_{m e t}\left(\frac{\delta_{m e t}}{H_{m e t}}\right)^{\alpha_{m e t}}\left(\frac{H}{\delta}\right)^{\alpha}
$$

where $U_{H}(\mathrm{~m} / \mathrm{s})$ is the local wind speed on the rooftop, $H$ $(m)$ the building height, and $U_{m e t}(\mathrm{~m} / \mathrm{s})$ the wind speed from a meteorological station. The coefficients $\alpha$ and amet and the thickness of boundary layer $\delta$ in Eq. (1) are related to terrain type (ASHRAE Handbook of Fundamentals, 2009).

We can use Eq. (1) to determine $U_{m e t}$ from measured $U_{H}$ because the relationship is linear. If $U_{H}$ contains extremes and large variations within one hour, $U_{\text {met }}$ must have the same behaviour. Meanwhile, Eq. (1) can also be applied to the average wind velocity in one hour:

$$
U_{\text {ave }}=U_{m e t, a v e}\left(\frac{\delta_{m e t}}{H_{m e t}}\right)^{\alpha_{m e t}}\left(\frac{H}{\delta}\right)^{\alpha}
$$

By combining Eqs. (1) and (2), we obtain

$$
U_{t} /_{U_{\text {ave }}}=U_{\text {met }, t} / U_{\text {met.ave }} \quad t=1, \ldots, 60 \mathrm{~min}
$$

If we consider $U_{t}$ and $U_{m e t, t}$ as minute-by-minute wind velocity, $U_{m e t, t}$ can be obtained from $U_{t}$ according to Eq. (3). Since the minute-by-minute wind information has a 
sufficiently small time interval, it should contain wind extremes and large variations. Note that we only considered the relationship between the wind speed at a meteorological station and that on a building rooftop. Therefore, this method has been verified only for those cases in which wind direction is relatively stable during the period concerned.

\section{Validation method for the correlation via field measurements of wind velocity}

With the $U_{m e t, t}$ from Eq. (3), one can use the coupled modeling method to determine the natural ventilation rate through an apartment for a period of time. If the measured cross-natural-ventilation rate is the same as the calculated rate, then the correlation method has been indirectly validated as reliable and accurate.

This investigation measured the wind velocity on a building rooftop and the cross-natural-ventilation rate through an apartment in Tianjin, China. Figure 2(a) shows the apartment building with a weather station P1 on the rooftop. The cross-ventilation rate was measured in a two-bedroom apartment on the third floor of the building. Figure 2(b) shows the floor plan of the apartment. Since our objective was to measure cross ventilation in the apartment, we artificially created a cross-ventilation passage inside the apartment as enclosed by the red lines in the figure. This passage was achieved by closing the hallway to the living room. Except for the south window, north window and interior doors that were open, all external windows were closed. Therefore, cross ventilation could occur only through the south and north windows. The opening of the south window was $0.15 \mathrm{~m}$ wide and $1.2 \mathrm{~m}$ high, and that of the north window was $0.15 \mathrm{~m}$ wide and $1.3 \mathrm{~m}$ high.

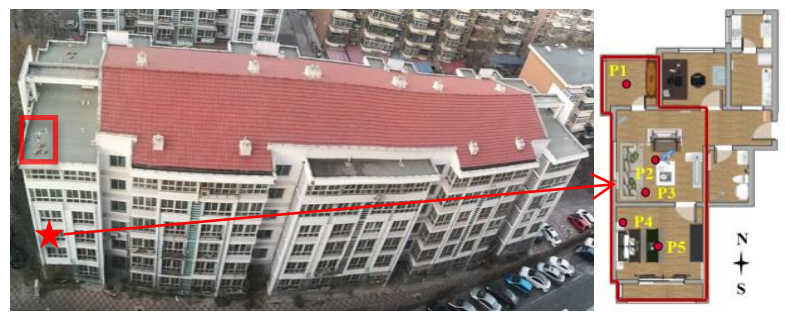

Figure 2: (a) A weather station installed on the rooftop of an apartment building and $(b)$ the floor plan of the apartment where cross-ventilation rate was measured.

This investigation used a $\mathrm{HOBO}$ micro weather station to measure the rooftop wind velocity and direction from March 8, 2018, to May 7, 2018. The measurement location was $2 \mathrm{~m}$ above the roof of the apartment building, as shown in Figure 2(a). The measuring frequency was one minute. The micro weather station had a measuring accuracy of $\pm 0.4 \%$ for wind speed if it was greater than $0.5 \mathrm{~m} / \mathrm{s}$, and \pm 50 for wind direction. The measured wind data can be used to convert the wind from the meteorological station in a Tianjin suburb to minute-by-minute data and to validate the simulated outdoor wind environment around the building.

To measure the cross-ventilation rate, this investigation used the tracer-gas-concentration decay method. Carbon dioxide was used as the tracer gas. Strictly, to obtain reliable results for the air change rate in an enclosure using the tracer-gas technique, the tracer gas should be uniformly mixed in the enclosure. However, complete mixing is difficult to achieve in a real building because of the complexity of the building's interior layout. Moreover, cross ventilation in the apartment involved four separated zones connected by three interior doors as shown in Figure 2(b), which further increased the complexity. According to Charlesworth (1998), one can overcome this problem by measuring the tracer-gas concentration at several locations. The mean of these concentrations can then be assumed to be the average concentration in the entire enclosure. Therefore, this investigation measured the $\mathrm{CO}_{2}$ concentration at five different locations, shown as P1 to P5 in Figure 2(b). Carbon dioxide was first released in each room, and two portable fans and one air-conditioning unit in ventilation mode were used to mix the $\mathrm{CO}_{2}$ with the room air. When the $\mathrm{CO}_{2}$ concentration at all five measuring locations reached about $5000 \mathrm{ppm}$, the $\mathrm{CO}_{2}$ injection, the fans, and the air-conditioning unit were all switched off. The south and north windows were then opened, while the $\mathrm{CO}_{2}$ concentrations at the five locations were continuously measured until the concentration reached $500 \mathrm{ppm}$. The measurements lasted from 30 to 90 minutes, depending on the outdoor airflow conditions. The tracer-gas-decay method was used to calculate the corresponding ventilation rate from the $\mathrm{CO}_{2}$ concentrations (Dai et al., 2018).

\section{Numerical procedure for computing cross-ventilation flow}

This investigation used a commercial CFD program, ANSYS Fluent 14.0 (ANSYS Fluent 14.0 User's Guide, 2011), to conduct the coupled modeling. The modeling used the unsteady Reynolds-averaged Navier-Stokes (RANS) equations with the RNG $\mathrm{k}-\varepsilon$ turbulence model (Shih et al., 1995) to solve the turbulent wind flow in the computational domain. The model has performed well in simulating urban wind flows (van Hooff and Blocken, 2013). The governing transport equations were solved by using the finite volume method. The species equation was utilized to calculate the transient decay of the $\mathrm{CO} 2$ concentration. The numerical method used the SIMPLE algorithm for coupling pressure and velocity equations, and the second-order discretization schemes for the convection and viscous terms of the governing equations. The modeling used the second-order implicit time integration for temporal discretization with a time step of 30 s. Van Hooff and Blocken (2013) compared three different time-step sizes $(\Delta t=5 \mathrm{~s}, 10 \mathrm{~s}$ and $30 \mathrm{~s})$ and found that the time-step size had no noticeable effect on the scaled residuals. In the present study, the results were considered converged when the residuals for all the independent parameters reached 10-4 at the end of each time step. For more detailed information about the numerical technique, please refer to the program manual (ANSYS Fluent 14.0 User's Guide, 2011).

Our previous study (Liu et al., 2018) proposed a fullscale model which can be used to calculate the wind flow around a building by using wind information from 
the nearest meteorological station. To achieve acceptable results, a CFD simulation should incorporate detailed structures around the building within a radius of at least three times the length scale, where the length scale is the maximum dimension of the building. Therefore, we used a full-scale model that extended from the apartment building with surrounding buildings within three length scales to the nearest nearby meteorological station, which was located $10 \mathrm{~km}$ away, as shown in Figure 3(a). The other regions were simplified with different roughness lengths, illustrated in different colors. The computational domain was $12.6 \mathrm{~km}$ long, $5.4 \mathrm{~km}$ wide and $0.351 \mathrm{~km}$ high. Figure 3(b) depicts the buildings within three length scales around the apartment building. Figure 3(c) illustrates the layout of the apartment used in the coupled modeling.

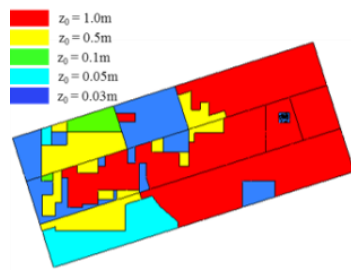

(a)

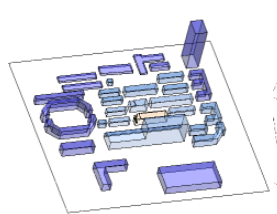

(b)

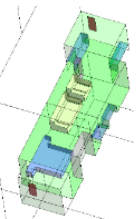

(c)
Figure 3: Geometric model used in this study: (a) fullscale model with detailed building structures around the apartment building within three length scales and different roughness lengths for the rest of the computational domain, $(b)$ detailed geometry of the apartment building with surrounding buildings within three length scales, and (c) layout of the apartment.

Gambit software (version 2.4.6) (GAMBIT CFD Preprocessor, 1998) was used to generate a discrete grid for discretizing the governing transport equations. Because of the complexity of the geometrical model, this study used a hybrid grid scheme with a tetrahedral grid, which can be adapted to various geometric structures. The grid size for the apartment shown in Figure 3(c) was $0.1 \mathrm{~m}$. The grid size for the domain shown in Figure 3(b) ranged from 1 to $7 \mathrm{~m}$, and for the remaining area shown in Figure 3(a) it ranged from 7 to $20 \mathrm{~m}$. The maximum grid size in the vertical direction was $10 \mathrm{~m}$. The resulting total grid number was 4.8 million. Figure 4(a) depicts the grid cell distribution for the apartment and Figure 4(b) the distribution around the building.

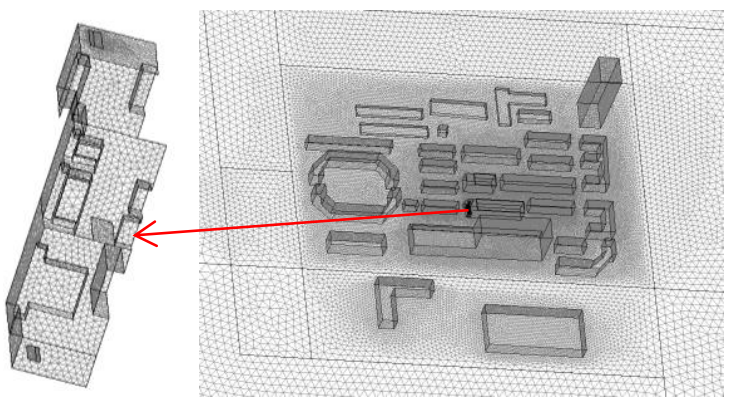

(a)

(b)

Figure 4: Grid cell distribution for (a) the apartment and $(b)$ the building surroundings.
The modeling used wind data from a meteorological station in the upwind direction as the inflow boundary conditions. The meteorological station was located 10 $\mathrm{km}$ southwest of the apartment building. This investigation selected the time period from 19:00 to 20:00 on April 18, 2018, for modelling the airflow around the building. The corresponding wind angles from the meteorological station at 19:00 and 20:00 were $220^{\circ}$ and $219^{\circ}$, respectively, which were from the southwest direction. Thus, the meteorological station was located in upstream of the apartment building. The simulation was able to set vertical western and southern boundaries in the computational domain as inflow. The two downstream vertical boundaries in the computational domain were modeled as outflow. The sky was treated as symmetric. The ground surface was simulated as non-slip conditions with roughness.

The roughness length $\left(z_{0}\right)$ for the ground surface between the meteorological station and the apartment region was determined from sand-grain roughness height $k_{s}$ and the roughness constant $C_{s}$ derived by Blocken et al. (2007):

$$
k_{s} C_{s}=9.793 z_{0}
$$

The simulations employed the standard wall function (Launder and Spalding, 1974; Cebeci and Bradshaw, 1977) to describe the sand-grain-based roughness. When the $k_{s}$ and $C_{s}$, are varied, Eq. (4) can be used to describe different aerodynamic roughness lengths, $z_{0}$, to take into account the influence of roughness elements on the wind flow field. Table 1 lists $z_{0}$ values for different terrains and the corresponding $k_{s}$ and $C_{s}$. Figure 3(a) shows the different roughness lengths used for the computational domain.

Table 1: Roughness for different terrains (Blocken et al., 2007; Wieringa, 1992).

\begin{tabular}{|c|c|c|c|}
\hline Type & $z_{\boldsymbol{0}}(\boldsymbol{m})$ & $\boldsymbol{k}_{\boldsymbol{s}}(\boldsymbol{m})$ & $\boldsymbol{C}_{\boldsymbol{s}}$ \\
\hline Grassland & 0.03 & 0.5 & 0.59 \\
\hline Few isolated obstacles & 0.05 & 1.0 & 0.5 \\
\hline $\begin{array}{c}\text { Low crops / Occasional large } \\
\text { obstacles }\end{array}$ & 0.1 & 1.0 & 1.0 \\
\hline $\begin{array}{c}\text { Parkland / Shrubs / Numerous } \\
\text { obstacles }\end{array}$ & 0.5 & 1.0 & 4.987 \\
\hline $\begin{array}{c}\text { Densely distributed mid-rise } \\
\text { and high-rise buildings }\end{array}$ & 1 & 1.0 & 9.793 \\
\hline
\end{tabular}

The wind speed measurements from the meteorological station $\left(U_{\text {met,ave }}\right)$ at 19:00 and 20:00 were both $1.8 \mathrm{~m} / \mathrm{s}$. According to Eq. (3), the correlated minute-by-minute wind speed, $U_{m e t, t}$, can be used to define the inflow profiles, $U_{z, t}$. The vertical velocity profile for the inflow boundary was modeled as a power law, and the vertical profiles for $k_{z, t}$ and $\varepsilon_{z, t}$ were taken from AIJ guidelines for practical applications of CFD to the pedestrian wind environment around buildings (Tominaga et al., 2008), as follows:

$$
\begin{gathered}
U_{z, t}=U_{r, t}\left(\frac{z}{z_{r}}\right)^{\alpha} \\
k_{z, t}=\left(I_{z, t} U_{z, t}\right)^{2} \\
\varepsilon_{z, t}=U_{A B L, t}^{*^{3}} / k\left(z+z_{0}\right)
\end{gathered}
$$

where 


$$
\begin{gathered}
I_{z, t}=0.1\left(\frac{z}{z_{G}}\right)^{(-\alpha-0.05)} \\
U_{A B L, t}^{*}=k U_{r, t} / \ln \left(\left(z_{r}+z_{0}\right) / z_{0}\right)
\end{gathered}
$$

The $U_{z, t}(\mathrm{~m} / \mathrm{s})$ is the minute-by-minute velocity profile $(\mathrm{m} / \mathrm{s})$. The $U_{r, t}(\mathrm{~m} / \mathrm{s})$ in Eq. (5) is the minute-by-minute velocity at reference height $z_{r}(m)$, and $z(m)$ is height. Because the meteorological station was located in a suburb, the exponent in the power law was $\alpha=0.22$ (ASHRAE Handbook Fundamentals, 2009) at the two inlet boundaries. The $k_{z, t}$ is the vertical distribution of turbulent energy. The $I_{z, t}$ in Eq. (6) is the minute-byminute turbulent intensity profile. The $\varepsilon_{z, t}$ is the turbulence dissipation profile. In Eq. (7). $U_{A B L}{ }^{*}$ is the atmospheric boundary layer friction velocity, while $\mathrm{k}$ is the Karman constant $(=0.4)$. The $z_{G}(m)$ in Eq. (8) is the boundary layer height $(=370 \mathrm{~m})$ determined by terrain category (ASHRAE Handbook Fundamentals, 2009).

\section{Results}

\section{Conversion of hourly wind speed to minute-by- minute data}

For conversion of hour-by-hour meteorological data from a meteorological station to minute-by-minute data, the wind direction during the period under consideration needs to be relatively stable. Figure 5(a) depicts the wind-direction variation on the rooftop from 19:00 to 20:00 on April 18, 2018, which was stable. According to [(http://data.cma.cn/)], the average for the first two minutes of an hour can be used to represent the hourly weather data. Therefore, the average wind speed for the first two minutes was used as the denominator in Eq. (3). Figure 5(b) depicts the minute-by-minute wind speed with the wind velocity from the meteorological station and the building rooftop from 19:00 to 20:00. The calculated wind speed was time-dependent and dynamic.

(a)
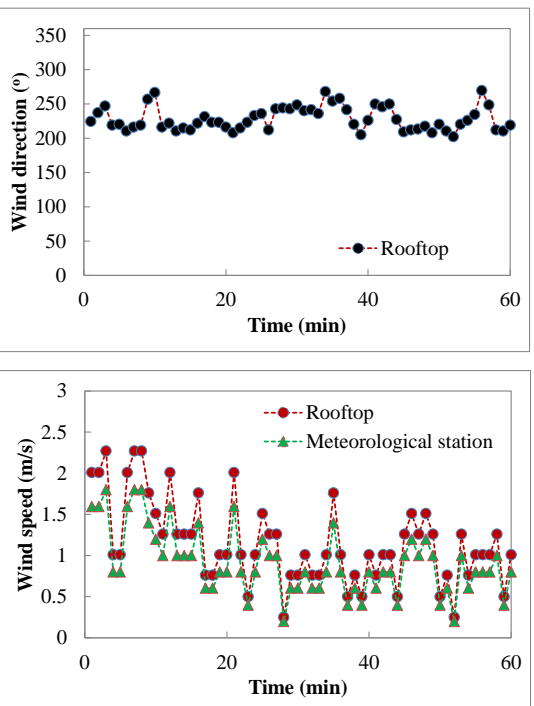

(b)

Figure 5: (a) The measured wind direction on the rooftop of the apartment building, and (b) the converted minute-by-minute wind speed with the wind velocity from the meteorological station and the building rooftop.

\section{Outdoor wind-speed simulations}

This investigation conducted unsteady CFD simulations by using the modified minute-by-minute meteorological wind information shown in Figure 5 as inflow boundary conditions. Figure 6 compares the simulated wind speed with the measured data on the rooftop of the apartment building. The numerical simulation results agreed well with the measured data. The mean relative error between the numerical results and the experimental data was $24.4 \%$. The error was acceptable for studying airflow around buildings, since there were many uncertainties that could have contributed to this error.

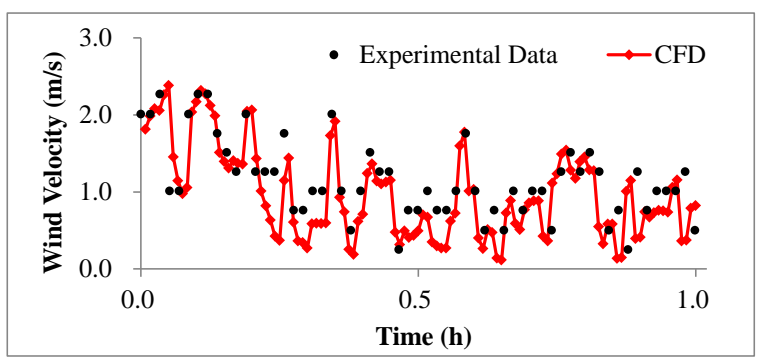

Figure 6: Comparison of the simulated wind speed with the measured data on the rooftop of the apartment building.

\section{Calculation of cross-ventilation flow rate}

The CFD simulation used in this investigation calculated not only the airflow around the building but also the airflow in the apartment, with the use of the coupled modeling method. At the same time, the simulation determined the $\mathrm{CO}_{2}$ concentration decay curves in the apartment by using the source information from the measurements. Figure 7 compares the simulated $\mathrm{CO}_{2}$ concentration decay with the measured data at the five measuring locations in the apartment (as indicated in Figure 2(b)). After 20 minutes, the simulated $\mathrm{CO}_{2}$ concentration decayed in the same way as that in the experiment. However, there were significant differences within the first 20 minutes.

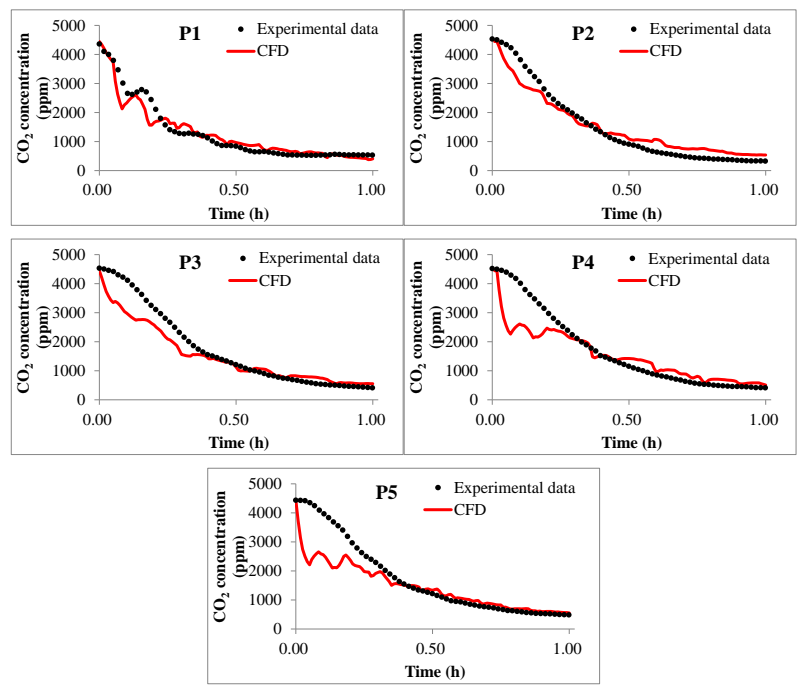

Figure 7: Comparison between measured and simulated $\mathrm{CO}_{2}$ concentration decay curves at the five locations.

For analysis of the differences, Figure 8 depicts the airflow around the building, the airflow in the apartment, 
and the indoor $\mathrm{CO}_{2}$ concentration distribution at a height of $7.9 \mathrm{~m}$ above the ground at different time steps, i.e., $\mathrm{t}=$ 3,10 , and $20 \mathrm{~min}$. At $\mathrm{t}=3 \mathrm{~min}$, the outdoor air flowed into the apartment through the southern window, as shown in the middle section of Figure 8(a). The average air velocity at the south window was $1.1 \mathrm{~m} / \mathrm{s}$. The $\mathrm{CO}_{2}$ concentration decreased considerably in the southern room (bedroom). The right-hand section of Figure 8(a) shows considerable spatial concentration gradients inside the apartment. Since the two exterior windows were located in the separation zones of the approaching wind around the apartment, as shown in the left-hand section of Figure 8(a), the amount of outdoor air entering or leaving the apartment through the windows was very sensitive to the wind direction and speed around the window areas. It is well known that the RNG k- $\varepsilon$ model has difficulty in predicting the separations accurately, and the discrepancy between the computed and measured $\mathrm{CO}_{2}$ concentration was large.

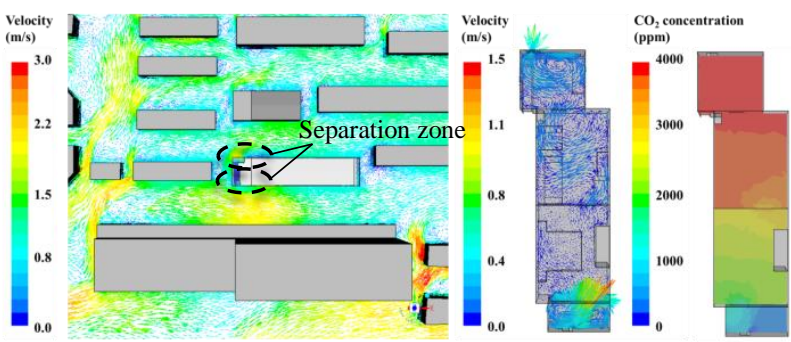

(a) $t=3 \min$

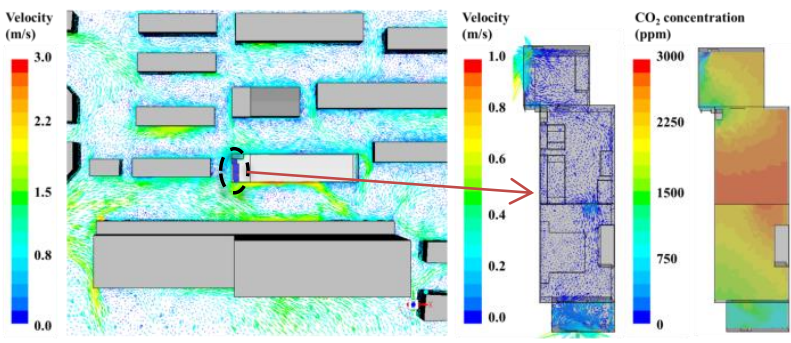

(b) $\mathrm{t}=10 \mathrm{~min}$

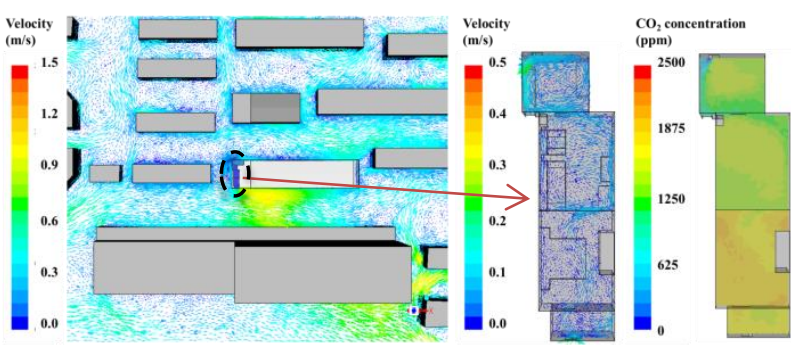

(c) $\mathrm{t}=20 \mathrm{~min}$

Figure 8: Airflow around the building (left), airflow in the apartment (middle), and indoor $\mathrm{CO}_{2}$ concentration distribution (right) at a height of $7.9 \mathrm{~m}$ above the ground at different time steps: (a) $t=3 \mathrm{~min}$, (b) $t=10 \mathrm{~min}$, and

$$
\text { (c) } t=20 \min . \text {. }
$$

At $\mathrm{t}=10 \mathrm{~min}$, the wind speed around the building became lower, as shown in the left-hand section of Figure 8(b). The two separation zones outside the exterior windows disappeared. The average air velocity at the south window was reduced to $0.6 \mathrm{~m} / \mathrm{s}$. The CFD simulation should be accurate, and, as a result, it narrowed the difference between the calculated and measured $\mathrm{CO}_{2}$ concentration in the apartment. Although the wind separation appeared again at $\mathrm{t}=20 \mathrm{~min}$, as illustrated in the left-hand section of Figure $8(\mathrm{c})$, the separation occurred only on the outside of the southern window, and the wind speed was again very low. The CFD simulation was able to predict the airflow through the apartment with good accuracy. From $t=20 \mathrm{~min}$ to $t$ $=60$ min, Figure 7 depicts a low wind speed, and our CFD simulation did not show again the separation on the outside of northern window. Therefore, the predicted $\mathrm{CO}_{2}$ concentration in the apartment agreed quite well with the measured data.

This investigation further calculated the air change rate in the apartment by using the tracer-gas-decay method (Dai et al., 2018) with the simulated and measured $\mathrm{CO}_{2}$ concentrations. Since significant differences existed in the first 20 minutes for the simulated results, this investigation calculated the air change rate through piecewise fitting at different time intervals, i.e., from $\mathrm{t}=$ 0 to $20 \mathrm{~min}$, from $\mathrm{t}=10$ to $20 \mathrm{~min}$, and from $\mathrm{t}=20$ to 60 min. Figure 9 compares the calculated air change rate with the measured data in the five measurement locations at different time intervals. As expected, from $t$ $=0$ to $10 \mathrm{~min}$, CFD calculated a $50 \%$ higher air change rate than the measured data because of the two separations of the wind outside the exterior windows of the apartment. From $\mathrm{t}=10$ to $20 \mathrm{~min}$, CFD underpredicted the air exchange rate in most of the locations in the apartment by an average of $37 \%$. As shown in Figure 6, the predicted wind speed was generally lower than the measured value during this period. The difference was smaller than during the first 10 minutes. From $\mathrm{t}=20$ to $60 \mathrm{~min}$, the air change rate predicted by CFD was higher than the in the experiment at locations P1, P2, and P3 but lower at P4 and P5. Although the tracer-gas method is effective for measuring the ventilation rate under steady-state conditions, the cross ventilation studied here was not steady. In addition, the CFD prediction still shows the wind separation outside the southern window. Because of the deficiency of the RNG k- $\varepsilon$ model and the tracer-gas method, the mean difference between the CFD result and experiment data during this period was $14 \%$ on average, which is acceptable for ventilation design.

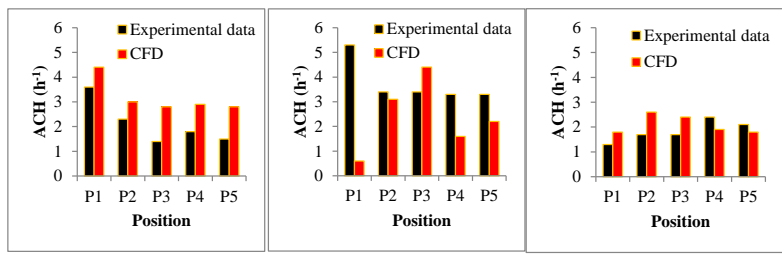

Figure 9: Comparison of the CFD-simulated and experimentally determined air change rate at the five locations in the apartment due to cross ventilation, at different time intervals: (a) from $t=0$ to $10 \mathrm{~min},(b)$ from $t=10$ to $20 \mathrm{~min}$, and (c) from $t=20$ to $60 \mathrm{~min}$.

\section{Conclusion}

This study performed CFD simulations with the unsteady RNG k- $\varepsilon$ model to calculate simultaneously the 
airflow around a building and the cross-ventilation through an apartment. The method used coupled modeling to perform these simultaneous calculations. The study led to the following conclusions:

- Traditional CFD simulations using constant wind speed do not consider the dynamic wind speed, which may cause errors. This investigation proposed a correlation method to convert hour-by-hour meteorological data from a meteorological station to minute-by-minute data.

- With the modified minute-by-minute data, the variation trend of the wind speed at the rooftop measuring location can be reproduced satisfactorily by the unsteady CFD simulation. The mean relative error between the experimental data and the numerical result was $24.4 \%$.

- When a modified inflow boundary condition is used, the CFD model can predict cross ventilation through the apartment. However, for the specific hour investigated here, the wind generated two separations outside the southern and northern exterior windows. Since the RNG $\mathrm{k}-\varepsilon$ model could not predict the separation accurately, there were significant difference between the predicted and measured air change rate in the apartment. The use of the tracer-gas method for the unsteady flow contributed further to the difference.

\section{Acknowledgement}

The research presented in this paper was partially supported by the National Key R\&D Program from the Ministry of Science and Technology, China, on "Green Buildings and Building Industrialization" through Grant No. 2016YFC0700500 and by the National Natural Science Foundation of China through Grant No. 51678395 .

\section{References}

Aflaki, A., Mahyuddin, N., Mahmoud,Z.A.C., Baharum, M. R., 2015. A review on natural ventilation applications through building faccade components and ventilation openings in tropical climates. Energy and Buildings 101, 153-162.

Aflaki, A., Hirbodi, K., Mahyuddin, N., Yaghoubi, M., Esfandiari, M., 2019. Improving the air change rate in high-rise buildings through a transom ventilation panel: A case study. Building and Environment 147, 35-49.

Almeida, R.M.S.F., Pinto, M., Pinho, de Lemos, P.G., L.T., 2017. Natural ventilation and indoor air quality in educational buildings: Experimental assessment and improvement strategies. Energy Efficiency 10, 839-854.

ANSYS Inc.. 2011. ANSYS Fluent 14.0 User's Guide. ANSYS Inc. Southpointe.

ASHRAE. 2008. ASHRAE Handbook Fundamentals (SI ed.), ASHRAE, Atlanta, GA.

Aynsley, R.M., 1988. A resistance approach to estimating airflow through buildings with large openings due to wind. ASHRAE Transactions 94, 1661-1669.
Blocken, B., Stathopoulos, T., Carmeliet, J., 2007. CFD simulation of the atmospheric boundary layer: wall function problems. Atmospheric Environment 41(2), 238-52.

Cebeci, T., Bradshaw, P., 1977. Momentum transfer in boundary layers. Hemisphere Publishing Corporation, New York.

Charlesworth, P.S., Charlesworth, P.S., 1988. Air exchange rate and airtightness measurement techniques - An applications guide, Air Infiltration and Ventilation Centre, Coventry, UK.

Cheng, J., Qi, D., Katal, A., Wang, L.L., Stathopoulos, T., 2018. Evaluating wind-driven natural ventilation potential for early building design. Journal of Wind Engineering and Industrial Aerodynamics 182, 160169.

Chen, Q., 2004. Using computational tools to factor wind into architectural environment design. Energy and Buildings 36, 1197-1209.

Chen, Y., Tong, Z., Malkawi, A., 2017. Investigating natural ventilation potentials across the globe: Regional and climatic variations. Building and Environment 122(Supplement C), 386-396.

Chu, C.-R., Wang, Y.W., 2010. The loss factors of building openings for wind-driven ventilation. Building and Environment 45(10), 2273-2279.

Dai, X., Liu, J., Yin, Y., Song, X., Jia, S., 2018. Modeling and controlling indoor formaldehyde concentrations in apartments: On-site investigation in all climate zones of China. Building and Environment 127, 98-106.

de Dear, R.J., Brager, G.S., 2002. Thermal comfort in naturally ventilated buildings: Revisions to ASHRAE Standard 55. Energy and Buildings 34, 549-561.

Etheridge, D., Sandberg M., 1996. Building ventilation: Theory and measurement. John Wiley and Sons, p. 93.

GAMBIT CFD Preprocessor. 1998. User's Guide. Lebanon, NH: Fluent Inc..

Hu, C.-H., Kurabuchi, T., Ohba, M., 2005. Numerical study of cross-ventilation using two-equation RANS turbulence models. International Journal of Ventilation 4 (2),123-131.

Jiang, Y., Alexander, D., Jenkins, H., Arthur, R., Chen, Q., 2003. Natural ventilation in buildings: Measurement in a wind tunnel and numerical simulation with large-eddy simulation. Journal of Wind Engineering and Industrial Aerodynamics 91, 331-353.

Jiang, Y., Chen, Q., 2002. Effect of fluctuating wind direction on cross natural ventilation in buildings from large eddy simulation. Building and Environment 37, 379-386. 
Launder, B.E., Spalding, D.B., 1974. The numerical computation of turbulent flows. Computer Methods in Applied Mechanics Engineering 3, 269-89.

Larsen, T. S., 2006. Natural ventilation driven by wind and temperature difference. Aalborg: Department of Civil Engineering, Aalborg University, (DCE Thesis; No. 2).

Liu, S., Liu, J., Yang, Q., Pei, J., Lai, D., Cao, X., Chao, J., Zhou, C., 2014. Coupled simulation of natural ventilation and daylighting for a residential community design. Energy and Buildings 68, 686695.

Liu, S., Pan, W., Zhang, H., Cheng, X., Long, Z., Chen, Q., 2017. CFD simulations of wind distribution in an urban community with a full-scale geometrical model. Building and Environment 117, 11-23.

Liu, S., Pan, W., Zhao, X., Zhang, H., Cheng, X., Long, Z., Chen, Q., 2018. Influence of surrounding buildings on windflow around a building predicted by CFD simulations. Building and Environment 140, $1-10$.

Martins, N.R., da Graça, G.C., 2016. Validation of numerical simulation tools for wind-driven natural ventilation design. Building Simulation 9(1), 75-87.

Perén, J.I., van Hooff, T., Leite, B.C.C., Blocken, B., 2015. CFD analysis of cross-ventilation of a generic isolated building with asymmetric opening positions: Impact of roof angle and opening location. Building and Environment 85, 263-276.

Ramponia, R., Blocken. B., 2012. CFD simulation of cross-ventilation flow for different isolated building configurations: Validation with wind tunnel measurements and analysis of physical and numerical diffusion effects. Journal of Wind Engineering and Industrial Aerodynamics 104-106,408-418.

Robaa, S.M., 2003. Urban-suburban/rural differences over Greater Cairo, Egypt. Atmósfera 16,157-171.

Shetabivash, H., 2015. Investigation of opening position and shape on the natural cross ventilation. Energy and Buildings 93, 1-15.

Shih, T.H., Liou, W,W., Shabbir, A., Yang, Z., Zhu. J., 1995. A new k- eddy-viscosity model for high Reynolds number turbulent flows-Model development and validation. Comput Fluids 24(3), 227-38.

Shirzadi, M., Naghashzadegan, M., Mirzaei, P.A., 2018. Improving the CFD modelling of cross-ventilation in highly-packed urban areas. Sustainable Cities and Society 37, 451-465.
Tominaga, Y., Mochida, A., Yoshie, R., Kataoka, H., Nozu, T., Yoshikawa, M., Shirasawa, T., 2008. AIJ guidelines for practical applications of CFD to pedestrian wind environment around buildings. Journal of Wind Engineering and Industrial Aerodynamics 96, 1749-1761.

Tong, Z., Chen, Y., Malkawi, A., Liu, Z., Freeman, R.B., 2016. Energy saving potential of natural ventilation in China: The impact of ambient air pollution. Applied Energy 179, 660-668.

van Hooff, T., Blocken, B. 2010a. On the effect of wind direction and urban surroundings on natural ventilation of a large semi-enclosed stadium. Computers \& Fluids 39, 1146-1155.

van Hooff, T., Blocken, B., 2010b. Coupled urban wind flow and indoor natural ventilation modelling on a high-resolution grid: A case study for the Amsterdam ArenA stadium. Environmental Modelling \& Software 25, 51-65.

van Hooff, T., Blocken, B., 2013. CFD evaluation of natural ventilation of indoor environments by the concentration decay method: $\mathrm{CO}_{2}$ gas dispersion from a semi-enclosed stadium. Building and Environment 61, 1-17.

van Hooff, T., Blocken, B., Tominaga, Y., 2017. On the accuracy of CFD simulations of crossventilationflows for a generic isolated building: Comparison of RANS, LES and experiments. Building and Environment 114, 148-165.

Wang, L., Wong, N.H., 2008. Coupled simulations for naturally ventilated residential buildings. Automation in Construction 17, 386-398.

Wieringa, J., 1992. Updating the Davenport roughness classification. Journal of Wind Engineering and Industrial Aerodynamics 41(1-3), 357-368.

Wu, W., Wang, B., Malkawi, A., Yoon, N., Sehovic, Z., Yan, B., 2018. A method toward real-time CFD modeling for natural ventilation. Fluids 3(4), 101.

Zhai, Z., Hamilton, S.D., Huang, J., Allocca, C., Kobayashi, N., Chen Q., 2000. Integration of indoor and outdoor airflow study for natural ventilation design using CFD. Proceedings 21st AIVC Annual Conference, "Innovations in Ventilation Technology," 26-29 September, paper 13.

Zhang, R., Mirzaei, P.A., Jones. B., 2018. Development of a dynamic external CFD and BES coupling framework for application of urban neighbourhoods energy modelling. Building and Environment 146, $37-49$ 